\title{
Analisis Implementasi Algoritma Penanganan Kegawat Pra Rumah Sakit Oleh Masyarakat sebagai First Responder di Surakarta
}

\author{
Widodo $^{1 *}$, Sumardino ${ }^{2}$ \\ ${ }^{1,2}$ Poltekkes Kemenkes Surakarta Jurusan Keperawatan \\ *Email: widd70@yahoo.com
}

\begin{abstract}
Background: Between 2006-2015, there were reported at least 6270 disasters affecting 5 continents. Of the total disasters, there were at least 8,197.66 people died, 70,597 survival nd damage to the economic sector was around 1,989,866,263 dollars. The safety of the victims are very dependent on various factors, therefore collaboration of the whole community is needed in providing first aid at the scene before getting help from the health setting. The purpose for this study is to describe the understanding of prehospital emergency management algorithms for the community as the first respondent in Surakarta. Methods: This study uses an pre experimental research design with the Pre-Test-Post Test Group design without control group with the subject of people of Surakarta City after recruited using consecutive sampling techniques and 222 respondent were finally recruited. After following pretest, respondents received training about the implementation of the firtst aid algorythm and post-test was delivered at the end. The variable in this study is the community's ability in providing first aid during emergency in the community. Result: A questionner was used to meassure knowledge before and after following training. Wilcoxon Match Pair test was used to compare the data from pre-test and post-test. The majority of subjects have good knowledge and increased knowledge after following training pertaining to be first responders. Conclusion: Training and simulation are essential in order to increase and maintain first responders capacity in providing aid before referring to health care setting. In addition, community needs to continue to be given socialization and understanding of the existence of PSC 119 so that the first aid that has been given optimally will get maximum further assistance.
\end{abstract}

Kata kunci: first responder, kegawatdaruratan, masyarakat, PSC 119

\section{PENDAHULUAN}

Kejadian bencana tidak dapat terprediksi, bahkan sering kali tidak dapat dicegah (Andrews \& Quintana, 2015). Bencana menimbulkan dampak baik terhadap individu, keluarga dan masyarakat, maupun infrastruktur bahkan negara sekalipun. Dampak akibat bencana sering menimbulkan korban, dan cidera yang memerlukan pertolongan yang cepat sebelum mendapatkan bantuan professional yang semestinya (Andrews \& Quintana, 2015; International Federation of Red Cross and Red Crescent Societies, 2016).

Pertolongan pertama pada kodisi kegawatdaruratan tidak hanya berkaitan dengan cedera fisik atau penyakit, tetapi juga termasuk perawatan pada awal terjadinya sakit atau terluka. Selain itu dukungan psikososial bagi penderita juga diperlukan penderita akibat tekanan emosional sebagai dampak dari peristiwa traumatis.

Tujuan dari pemberian pertolongan pertama adalah untuk menyelamatkan penderita dari kematian, mengurangi penderitaan, mencegah penyakit atau cedera lebih lanjut atau kecacatan dan meningkatkan pemulihan (Qalil et al., 2019). International Federation of Red Cross and Red Crescent Societies (2016) menyebutkan secara prinsip terdapat dua komponen keselamatan penolong yang harus diutamakan yaitu keselamatan dari kondisi lingkungan dan keselamatan dari potensi penularan. 
Secara geografis, letak Indonesia yang berada di cincin api (ring of fire) sangat tinggi terhadap resiko terjadinya gempa bumi yang berpotensi diikuti tsunami maupun gunung meletus. Secara hidrologi Indonesia juga sangat rentan terhadap bencana alam seperti banjir, longsor angin topan dan sebagainya (Satrio, 2018). Kemajuan pembangunan juga tidak terlepas dari potensi kecelakaan yang dapat berujung pada kejadian cidera bahkan sampai menimbulkan kematian.

Ketangguhan terhadap bencana diperlukan oleh seluruh lapisan masyarakat. Masyarakat perlu memiliki kesadaran, pengetahuan, keterampilan, dan kepedulian menolong terhadap sesama untuk menghidari jatuhnya korban yang tinggi, karena potensi-potensi bencana tersebut tidak dapat dihilangkan. Pemerintah telah membuat Sistem Penanggulangan Gawat Darurat Terpadu (SPGDT), untuk mempercepat penanganan korban.

Sistem penanggulangan pasien gawat darurat yang terdiri dari unsur pelayanan di masyarakat atau sebelum sampai ke rumah sakit, pelayanan di (intra) rumah sakit dan pelayanan antar rumah sakit. Pelayanan dengan respon cepat menjadi penekan jumlah korban, dengan selalu menghemat waktu untuk keselamatan nyawa dan menghindari kecacatan, yang melibatkan pelayanan oleh masyarakat, petugas kompeten (perawat dan medis), pelayanan ambulans gawat darurat dan sistem komunikasi (Kementerian Kesehatan RI, 2016). Baik buruknya penanganan gawat darurat bisa dilihat dari kecepatan respons yang diberikan dari jarak waktu saat terjadi peritiwa, sampai datang pertolongan. Kecepatan meminta pertolongan dan kecepatan datangnya pertolongan juga termasuk dalam waktu respon. Penyelenggaraan SPGDT menurut Peraturan Menteri Kesehatan Republik Indonesia (Kementerian Kesehatan RI, 2016) dibagi menjadi tiga yaitu sistim komunikasi gawat darurat, sistim penanganan korban atau pasien gawat darurat dan sistim transportasi gawat darurat.

Pemerintah membentuk Pusat Komando Nasional (National Command Center) yang berkedudukan di bawah Kementerian Kesehatan dan ditanggungjawabi oleh Direktur Jenderal yang bertanggungjawab dalam mengelola sistim komunikasi gawat darurat. Setiap Pemerintah Daerah baik Kabupaten maupun Kota wajib dibentuk Public Safety Center (PSC) 119, sebagai pusat layanan terdepan, yang berkedudukan di Dinas Kesehatan, Rumah Sakit, lokasilokasi lain yang ditetapkan oleh pemerintah daerah. Fungsi PSC 119 meliputi memberikan pelayanan korban pasien gawat darurat dan atau pelapor melalui proses triase (pemilahan kondisi korban atau pasien gawat darurat, pemandu pertolongan pertama (first aid), pengevakuasi korban atau pasien gawat darurat, dan pengkoordinasi dengan fasilitas pelayanan kesehatan (Kemeterian Kesehatan RI, 2016).

Menurut Comprehensive Guide for First Aid \& CPR Table of Contents (2017) ada 4 peran penolong pertama yang harus diperhatikan yaitu mengenali kondisi kegawatan, melindungi diri penolong, penderita atau yang terluka serta masyarakat sekitar kejadian, meminta pertolongan (acces) pertolongan misalnya 119 dan bertindak sesuai batas pengetahuan, keterampilan yang dimilikinya dan kenyamanannya. Masyarakat di sekitar kejadian adalah 
orang yang pertama dapat memberikan pertolongan (first responder). Peran serta masyarakat sangat diharapkan dapat memberikan kontribusi pada penanganan kegawatdaruratan tersebut sejak masih berada di tempat kejadian. Keberadaan masyarakat sebagai penolong pertama (MPP) atau Community First Responder $(C F R)$ yaitu seseorang yang secara sukarela memberikan bantuan medis darurat dalam komunitas di mana berada terutama pada daerah-daerah yang agak sulit terjangkau oleh pertolongan ambulan. Kelompak masyarakat relawan ini bekerja tidak atas nama ambulans atau tim PSC 119 tetapi murni atas panggilan jiwa untuk memberikan pertolongan pertama sebelum penyintas mendapatkan pertolongan dari ambulans atau tim PSC 119.

Agar dapat mendapatkan pertolongan yang lebih maksimal dibutuhkan kapasitas dan kemampuan penolong yang memadahi. Pertolongan pertama sangat menentukan keberhasilan pertolongan selanjutnya, meskipun tetap dipengaruhi oleh faktor lain seperti berat ringannya permasalahan yang terjadi, kondisi lingkungan, keberadaan dan kemampuan penolong dan sebagainya. Kemampuan atau kompetensi penolong yang baik memerlukan pengetahuan dan keterampilan yang cukup serta pengalaman yang memadahi. Adanya pengetahuan yang memadahi diharapkan masyarakat dapat segera melakukan pertolongan dengan benar terhadap berbagai kejadian kegawatdaruratan sesuai kompetensi yang dimilikinya. Dengan demikian peluang keselamatan korban semakin besar. Tujuan dari penelitian ini adalah untuk menggambarkan pengetahuan algoritma manajemen gawat darurat pra rumah sakit bagi masyarakat sebagai responden pertama di Surakarta

\section{METODE PENELITIAN}

Penelitian ini merupakan preexperiment research design dengan pendekatan pre-post test group yang dilaksanakan pada bulan Agustus 2019 di wilayah binaan Puskesmas Sibela Mojosongo Surakarta yang sebelumnya sudah dilakukan pemilihan secara acak. Dari jumlah populasi sebanyak 524 orang, setelah dihitung dengan rumus Slovin maka ditemukan 228 responden sebagai sample penelitian. Kriteria inklusi yang ditentukan meliputi masyarakat yang berusia 20-60 tahun, tidak sedang menderita penyakit, bukan anggota PSC 119.

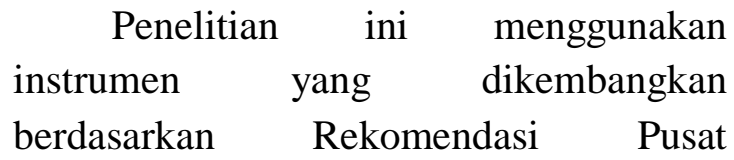
Penanggulangan Krisis Kesehatan Kemenkes RI dan dilakukan pengujian validitas dengan expert validity. Tiga orang ahli di bidang kegawatdaruratan diminta melakukan penilaian kevalidan instrumen (expert judgement) yang digunakan dan setelah dilakukan perbaikan dan dinyatakan valid. Selanjutnya setelah dilakukan uji pilot study kepada 20 responden di dilayah lainnya diperoleh hasil pengujian $r$ hitung 0.879-0.915, dapat dijelaskan bahwa nilai $r$ hitung $>r$ tabel berdasarkan uji signifikan 0.05 , artinya bahwa itemitem tersebut valid.

Berdasarkan hasil pengujian reliability Statistics Cronbach's Alpha N 
of Item < 90725 dari hasil uji reliabilitas didapatkan bahwa $r$ alpha $(0,907)>r$ table (0,351).

Maka semua pertayaan dinyatakan reliabel. Kelaikan etik diperoleh dari Komite Etik Penelitian Kesehatan (KEPK) Poltekkes Kemenkes Surakarta No.LB.02.02/1.3/1683/2019 tertanggal 8 April 2019 yang menyatakan bahwa penelitian ini dinyatakan memenuhi kaidah etik penelitian dengan subyek manusia.

\section{HASIL PENELITIAN}

Pengambilan data dilaksanakan pada bulan September tahun 2019 dan diperoleh 222 kuiesioner yang dikembalikan, dan yang memenuhi persyarataan untuk ditindaklanjuti ke tahap pengolahan data. Data demografik berupa data jenis kelamin, tingkat pendidikan, umur dan pekerjaan serta pengalaman memberikan pertolongan kegawatdaruratan pertama pra rumah sakit. Semua data ditampilkan dalam bentuk distribusi frekuensi.

Tabel 1. Distribusi Frekuensi Subyek menurut Jenis Kelamin, Tingkat Pendidikan Umur, Jenis Pekerjaan dan Pengalaman Menolong.

\begin{tabular}{lcc}
\hline Jenis Kelamin & Frekuensi & Persentase (\%) \\
\hline Laki - laki & 49 & $22.1 \%$ \\
Perempuan & 173 & $77.9 \%$ \\
\hline Jumlah & 222 & 100 \\
\hline Tingkat Pendidikan & Frekuensi & Persentase (\%) \\
\hline SD & 12 & $5.4 \%$ \\
SMP & 28 & $12.6 \%$ \\
SMA & 148 & $66.7 \%$ \\
DIII & 15 & $6.8 \%$ \\
DIV/SI & 19 & $8.6 \%$ \\
\hline Jumlah & 222 & 100 \\
\hline Umur & Frekuensi & Persentase (\%) \\
\hline Kurang / sama 30 Th & 31 & $14.0 \%$ \\
Antara 31 - 45 Th & 67 & $30.2 \%$ \\
Lebih / sama 46 Th & 124 & $55.9 \%$ \\
\hline Jumlah & 222 & 100 \\
\hline Jenis Pekerjaan & Frekuensi & Persentase (\%) \\
\hline Pelajar/ Mahasiswa & 17 & $7.7 \%$ \\
Swasta & 59 & $26.6 \%$ \\
Ibu Rumah Tangga & 98 & $44.1 \%$ \\
Pegawai Negeri & 12 & $5.4 \%$ \\
Pensiunan & 8 & $3.6 \%$ \\
Lain-Lain & 28 & $12.8 \%$ \\
\hline Jumlah & 222 & 100 \\
\hline Pengalaman Menolong & Frekuensi & Persentase (\%) \\
\hline Belum pernah menolong & 165 & $74.3 \%$ \\
Pernah menolong & 57 & $25.7 \%$ \\
\hline Jumlah & & 100 \\
\hline
\end{tabular}


Berdasarkan tabel 1, distribusi jenis kelamin perempuan menjadi kelompok mayoritas yaitu 143 subyek (77.9\%). Pendidikan terakhir Sekolah Menengah Atas (SMA) sebanyak 148 subyek (66.7\%) diikuti subyek dengan pendidikan terakhir Sekolah Menengah Pertama (SMP) sebanyak 28 subyek (12.6\%). Subyek dengan pendidikan terakhir Sekolah Dasar (SD) menempati urutan terakhir sebanyak 12 subyek (5.4\%).
Mayoritas subyek berusia lebih dari 45 tahun sebanyak 124 orang (55.9\%). Dari jenis pekerjaan, mayoritas subyek adalah ibu rumah tangga yaitu sebanyak 98 orang (44.1\%) diikuti pegawai swasta sebanyak 59 orang $(26.6 \%)$. Sebanyak 165 subyek $(74.3 \%)$ belum pernah memberikan pertolongan pertama kegawatdaruratan, sisanya 57 subyek $(25.7 \%)$ memiliki pengalaman dalam memberikan pertolongan pertama kegawatdaruratan.

Tabel 2. Distribusi Frekuensi Pre Test dan Post Test Subyek menurut Alogaritma Meminta Pertolongan PSC 119, Tersedak dan Henti Jantung

\begin{tabular}{|c|c|c|c|c|c|}
\hline \multicolumn{3}{|c|}{ Pre Test } & \multicolumn{3}{|c|}{ Post Test } \\
\hline Skala & Frekuensi & Persen (\%) & Skala & Frekuensi & Persen (\%) \\
\hline Rendah & 0 & $0 \%$ & Rendah & 0 & $0 \%$ \\
\hline Sedang & 93 & $41.9 \%$ & Sedang & 64 & $28.8 \%$ \\
\hline Tinggi & 129 & $58 \%$ & Tinggi & 158 & $71.2 \%$ \\
\hline Jumlah & 222 & $100 \%$ & Jumlah & 222 & $100 \%$ \\
\hline \multicolumn{3}{|c|}{ Pre Test } & \multicolumn{3}{|c|}{ Post Test } \\
\hline Skala & Frekuensi & Persen (\%) & Skala & Frekuensi & Persen (\%) \\
\hline Rendah & 67 & $30.2 \%$ & Rendah & 0 & $0 \%$ \\
\hline Sedang & 149 & $67.1 \%$ & Sedang & 57 & $25.7 \%$ \\
\hline Tinggi & 6 & $2.7 \%$ & Tinggi & 165 & $74.3 \%$ \\
\hline Jumlah & 222 & $100 \%$ & Jumlah & 222 & $100 \%$ \\
\hline & Pre Test & & \multicolumn{3}{|c|}{ Post Test } \\
\hline Skala & Frekuensi & Persen (\%) & Skala & Frekuensi & Persen (\%) \\
\hline Rendah & 22 & $9.9 \%$ & Rendah & 0 & $0 \%$ \\
\hline Sedang & 171 & $77.0 \%$ & Sedang & 129 & $58.1 \%$ \\
\hline Tinggi & 29 & $13.1 \%$ & Tinggi & 93 & $41.9 \%$ \\
\hline Jumlah & 222 & $100 \%$ & Jumlah & 222 & $100 \%$ \\
\hline
\end{tabular}

Tabel 2. menunjukkan adanya sebagian kecil subyek yaitu 22 orang perubahan pada kemampuan subyek (9.9\%) dengan pengetahuan yang rendah dalam meminta pertolongan atau bantuan ke PSC 119. Kemampuan tertinggi subyek dalam meminta pertolongan PSC 119 sebelum mendapatkan pelatihan hanya 6 subyek $(2.7 \%)$ setelah mendapatkan pelatihan menjadi 165 subyek (74\%) dan tidak ada subyek yang memiliki kapasitas rendah dalam meminta pertolongan PSC 119. sebelum mendapatkan pelatihan.

Sebagian besar subyek telah memahami dengan skala sedang, cara memberikan pertolongan pada orang yang mengalami tersedak. Setelah dilakukan pelatihan, sudah tidak ada subyek yang memiliki pemahaman yang rendah, bahkan semua subyek sudah memiliki pemahanan yang baik dimana Berkaitan pertolongan pertama tersedak, pada tingkat sedang sebanyak 129 
(58.1\%) dan tingkat tertinggi sebanyak 93 subyek (41.9\%). Pengetahuan subyek dalam pertolongan henti jantung tertinggi sebelum pelatihan sebanyak 129 (58\%) meningkat menjadi 158 (71.2\%). Pemberian pelatihan algoritma pertolongan pertama kegawatdaruratan sangat berpengaruh pada peningkatan pengetahuan subyek. Hal ini terlihat dari hasil statistik diketahui Asymp.sig (2tailed) bernilai 0.000. Dapat diartikan ada perbedaan yang signifikan antara pre test dan post test.

\section{PEMBAHASAN}

Pemberian pelatihan algoritma pertolongan pertama kegawatdaruratan berpengaruh pada peningkatan pengetahuan penolong. Haldane et al., (2019) menegaskan bahwa partisipasi masyarakat dapat memberikan kontribusi dalam pengembangan, implementasi, dan evaluasi pemberian layanan kesehatan, meskipun tidak dipungkiri terdapat berbagai tantangan dalam pelibatannya. Peran perempuan dalam memberikan kontribusi dalam pertolongan kegawat daruratan akibat bencana di berbagai negara sangat variatif (Hemachandra, Amaratunga, \& Haigh, 2018). Namun demikian sudah saatnya perempuan mendapatkan porsi yang tepat untuk dilibatkan dalam upaya kesiapsiagaan pertolongan pertama dalam kondisi darurat.

Dominasi perempuan pada penelitian ini menunjukkan adanya kesadaran perempuan untuk lebih berperan aktif dalam berbagai aspek kehidupan dan adanya kesempatan emansipasi yang didorong oleh pemerintah di tengah-tengah masih adanya dominasi kaum laki-laki di beberapa sektor kehidupan lainnya (The
Asia Foundation, 2012). Kondisi serupa juga ditemukan pada penelitian yang dilakukan oleh Sasson et al., (2013) dimana $85 \%$ responden dari total 39 adalah perempuan. Berbeda dengan hasil penelitian yang dilakukan oleh Phung, Trueman, Togher, Orner, \& Siriwardena, (2017) dimana dari 16 responden $75 \%$ diantaranya adalah laki-laki.

Demikan juga kaitannya dengan pendidikan yang merupakan dasar dari pengembangan pengetahuan dan keterampilan interpersonal maupun kompetensi lainnya. Lebih dari setengah responden telah menyelesaikan sekolah wajib 12 tahun. Pembangunan sumber daya manusia yang siap siaga menghadapi kondisi darurat akan lebih mudah dicapai dengan dasar pendidikan yang memadahi. Pembekalan pertolongan pertama pada kondisi gawat darurat bertujuan untuk melakukan pencegahan, membangun masyarakat yang lebih aman dan memiliki daya tahan, dan meningkatkan kapasitas jangka panjang dalam memperbaiki program-program kesehatan serta pengembangan masyarakat (International Federation of Red Cross and Red Crescent Societies, 2016). Adanya kesadaran masyarakat bahwa mereka harus mampu mengidentifikasi sendiri berada pada daerah atau situasi yang perpotensi terhadap bencana dan dapat mengancam keselamatannya. Dengan kesadaran ini maka masyarakat diharapkan dapat mulai memberikan kontribusi dalam menjaga keselamatan diri sendiri dan mampu mengidentifikasi resiko yang dihadapi dan kemampuan mereka dalam mengendalikan resiko serta mengelola situasi yang gawat (International Federation of Red Cross and Red Crescent Societies, 2016). 
Pekerjaan responden perempuan, yaitu sebagai pegawai atau karyawan di sektor swasta maupun sebagai ibu rumah tangga yang hampir setengah jumlah subyek memungkinkan tingginya interaksi dengan lingkungan pekerjaan atau minimal lingkungan rumah. Kemampuan memberikan pertolongan tidak hanya ditujukan pada orang terdekat dalam rumah namun juga dimanapun saat berada di tengah-tengah masyarakat. Kesadaran subyek untuk ikut secara sukarela terlibat dalam penelitian ini memberikan indikasi adanya rasa kesukarelawanan untuk membantu orang lain pada saat terjadi bencana (Kerr, Harmon, Marshall, Proescholdbell, \& Waller, 2014).

Peristiwa bencana yang memakan korban yang banyak telah menyadarkan banyak negara untuk mengembangkan sistim pengelolaan atau managemen bencana. Salah satu yang menjadi dasar pengelolaan ini adalah tersedianya masyarakat yang memiliki kapasitas yang baik dalam pertolongan. Penolong pertama ini harus segera memberikan respon pertolongan dengan didahului memanggil bantuan ambulan.

Keberadaan PSC 119 belum sepenuhnya dikenal oleh masyarakat padahal komunikasi yang efektif dengan PSC diharapkan dapat meningkatkan keselamatan dan mengurangi koban baik cacat maupun meninggal. Selain itu protokol atau algoritma pertolongan pertama kegawatdaruratan bagi masyarakat juga sangat diperlukan. Dari berbagai penelitian telah menunjukkan bahwa pertolongan pertama oleh masyarakat sangat berkontribusi pada keberhasilan pertolongan. Gabriel Riva, Mattias Ringh, Martin Jonsson, Leif Svensson, Johan Herlitz, Andreas Claesson, Therese Djärv, Per Nordberg,
Sune Forsberg, Sten Rubertsson, Anette Nord, Mårten Rosenqvist, (2019) menyatakan adanya peningkatan jumlah keselamatan penyintas setelah mendapatkan pertolongan kompresi jantung pada kasus henti jantung di luar rumah sakit dibandingkan tidak dilakukan kompresi dada.

Pada beberapa kondisi kegawatan sebagian masyarakat sudah memiliki dasar pengetahuan mengenai pertolongan pertama seperti pada pertolongan henti jantung, cidera atau trauma kepala maupun kejang demam. Ketersediaan masyarakat terlatih sebagai penolong pertama sangat berpengaruh terhadap keberhasilan pertolongan. Hoque et al., (2017) menemukan dari penyintas yang mendapatkan pertolongan pertama mengalami cidera yang berat dan ditemukan penyintas yang selamat setelah ditolong oleh penolong terlatih lebih banyak 1,28 kali dibanding dengan penyintas yang ditolong oleh penolong yang tidak terlatih.

Kasus tersedak meskipun tidak sering terjadi namun sering menimbulkan kepanikan bagi penderita. Besar kecilnya dampak yang ditimbulkan sangat tergantung dari besar kecilnya sumbatan dan kecepatan untuk membebaskan saluran nafas dari sumbatan. Sumbatan total dapat menyumbat saluran nafas secara total sehingga penderita tidak dapat bernafas sama sekali sehingga jika tidak segera mendapatkan pertolongan dapat menimbulakan kematian (Comprehensive Guide for First Aid \& CPR Table of Contents, 2017).

Kelompok usia yang paling rentang mengalami kematian adalah usia lanjut (Pavitt et al., 2017). Sebagaimana yang diungkapkan oleh Commission, (2010) yang menyebutkan angka kematian akibat 
tersedak makanan pada usia lanjut di mana terdapat peningkatan dengan faktor sekitar 1,2 kali selama 10 tahun terakhir. Kejadian tersedak juga sering terjadi pada anak-anak 0-4 tahun (Haldane et al., 2019). Anak-anak juga perlu perhatian khusus terhadap makanan yang dikonsumsi juga mainan yang berpotensi dimasukkan ke dalam mulut yang dapat beresiko mengakibatkan tersedak.

Pengetahuan masyarakat dan orang tua yang memiliki anak-anak dibawah lima tahun dalam memberikan pertolongan pertama pada penyintas yang mengalami tersedak merupakan bekal awal yang baik sebagai dasar penyelamatan penyintas. Ketika saluran nafas sudah terbebaskan maka pertolongan selanjutnya dapat dilakukan seperti pertolongan henti jantung dan sebagainya. $\quad$ AHA 2017 merekomendasikan masyarakat untuk melakukan kompresi dada segera pada penyintas yang mengalami henti jantung untuk dapat segera mengembalikan peredaran darah yang masih ada dalam sistim sirkulasi, untuk segera diedarkan ke organ-organ tubuh vital khususnya jantung dan otak. Seminar dan pelatihan diperlukan agar pengetahuan dan keterampilan masyarakat sebagai penolong pertama dapat selalu terbaharui (up date) berdasar new evidence.

Kemampuan melakukan cardiopumonary resuscitation (CPR) bagi masyarakat menjadi modal pertolongan penderita henti jantung (cardiac arrest) di masyarakat (Wang, Ma, \& Lu, 2015). Keterampilan ini harus selalu disegarkan melalui pelatihan-pelatihan sehingga keakuratan dalam memberikan pertolongan dapat terjaga. Lebih dari itu dengan pelatihan-pelatihan yang periodik maka temuan-temuan baru terkait keterampilan tersebut senantiasa dapat disesuaikan. Go et al., (2013) menyebutkan di mana setidaknya terdapat lebih dari 350.000 penderita henti jantung mendadak pra rumah sakit setiap tahunnya.

Tingginya penderita henti jantung pra rumah sakit juga dialami oleh kelompok masyarakat dari ras AfrikaAmerika, Latin, dan kalangan warga yang miskin dan mereka cenderung kurang mendapatkan kesempatan pertolongan CPR dengan baik di masyarakat (Sasson et al., 2013). Temuan yang menarik di mana seluruh subyek pada penelitian ini memiliki pengetahuan tentang CPR dengan baik dan sangat baik. Seiring dengan temuan ini yaitu sebagian subyek pernah memiliki pengalaman memberikan pertolongan pertama kegawatdaruratan pra rumah sakit.

Pencanangan wilayah Mojosongo sebagai kelurahan siaga telah mengkondisikan sebagian masyarakat yang aktif dalam pertolongan pertama terpapar dengan kegiatan-kegiatan pertolongan pertama. Sebagaimana yang ditemukan oleh (Sasson et al., 2013), 88 $\%$ responden dari 41 merasa telah mengenal CPR dengan baik bahkan $68 \%$ diantaranya sudah dengan formal pernah mengikuti kursus atau pelatihan CPR. Namun demikian terdapat beberapa kendala dalam upaya untuk mendapatkan atau meningkatkan keterampilan tersebut yaitu belum tersedianya sarana pelatihan CPR yang memadahi dan merata di seluruh lapisan masyarakat.

\section{KESIMPULAN DAN SARAN}

Dari hasil temuan pada penelitian ini maka dapat disimpulan beberapa hal mendasar bahwa karakteristik masyarakat sebagai penolong pertama sangat 
bervariatif dari berbagai aspek demografi maupun pengalaman memberikan pertolongan. Dominasi kelompok perempuan dengan usia lebih dari 46 tahun, yang mayoritas sebagai ibu rumah tangga dengan latar pendidikan yang cukup baik. Public Safety Center (PSC) 119 belum cukup dikenal oleh masyarakat sebagai pusat komando pertolongan kegawatdaruratan sehari-hari. Selain itu sebagian besar masyarakat sebagai penolong pertama telah memiliki latar belakang pendidikan dalam pertolongan pertama kegawatdaruratan sehari-hari dengan cukup baik bahkan beberapa sangat baik.

Beberapa saran yang dapat diupayakan antara lain karakteristik dari mayoritas subyek sebagai penolong pertama memberikan optimisme tersendiri dalam upaya kesiapsiagaan masyarakat menolong dirinya sendiri di bidang kegawatdaruratan, mengingat keberadaan mereka di tengah-tengah masyarakat dengan kapasitas dan pengalaman yang dimilikinya. Sosialisasi terhadap masyarakat terhadap keberadaan PSC 119 perlu terus dilakukan agar komunikasi dan koordinasi pertolongan pertama kegawatdaruratan semakin tertata dan terstandar dengan baik. Kondisi ini menjadi modal yang sangat baik sebagai bentuk kesiapsiagaan masyarakat untuk menjadi penolong pertama kegawatdaruratan sehari-hari

\section{DAFTAR RUJUKAN}

Andrews, R. J., \& Quintana, L. M. (2015). Unpredictable, unpreventable and impersonal medicine: Global disaster response in the 21 st century. EPMA Journal, Vol. 6. https://doi.org/10.1186/s13167-0140024-9
Commission, F. S. (2010). Risk Assesment Report Choking Accidents Caused by Foods Contents. (June).

Commission, H. (2007). The role and management of community first responders - Findings from a national survey of NHS ambulance services in England. Retrieved from https:/www.bristol.gov.uk/committe e/2008/wa/wa048/0418_7.pdf

Comprehensive Guide for First Aid \& CPR Table of Contents. (2017). 1228.

Gabriel Riva, Mattias Ringh, Martin Jonsson, Leif Svensson, Johan Herlitz, Andreas Claesson, Therese Djärv, Per Nordberg, Sune Forsberg, Sten Rubertsson, Anette Nord, Mårten Rosenqvist, J. H. (2019). Survival in Out.

Go, A. S., Mozaffarian, D., Roger, V. L., Benjamin, E. J., Berry, J. D., Borden, W. B., ... Turner, M. B. (2013). Heart Disease and Stroke Statistics2013 Update. Circulation, 127(1). https://doi.org/10.1161/cir.0b013e31 $828124 \mathrm{ad}$

Haldane, V., Chuah, F. L. H., Srivastava, A., Singh, S. R., Koh, G. C. H., Seng, C. K., \& Legido-Quigley, H. (2019). Choking is a leading cause of injury and death among children -ScienceDaily. Retrieved from http://www.sciencedaily.com/release s/2010/02/100226212559.htm

Hemachandra, K., Amaratunga, D., \& Haigh, R. (2018). Role of women in disaster risk governance. Procedia 
Engineering, 212(2017), 1187-1194. https://doi.org/10.1016/j.proeng.2018 .01.1533. (n.d).

Hoque, D. M. E., Islam, M. I., Salam, S. S., Sadeq-Ur Rahman, Q., Agrawal, P., Rahman, A., ... Alonge, O. (2017). Impact of first aid on treatment outcomes for non-fatal injuries in rural Bangladesh: Findings from an injury and demographic census. International Journal of Environmental Research and Public Health, Vol. 14. https://doi.org/10.3390/ijerph140707 62

International Federation of Red Cross and Red Crescent Societies. (2016). Resuscitation and first aid. 190.

Kementerian Kesehatan RI. (2016). Peraturan Menteri Kesehatan Nomor 19 Tahun 2016 tentang Sistem Penangulangan Gawat Darurat Terpadu. Berita Negara Republik Indonesia Tahun 2016, 19(5), 1-17.

Kerr, Z. Y., Harmon, K. J., Marshall, S. W., Proescholdbell, S. K., \& Waller, A. E. (2014). The epidemiology of traumatic brain injuries treated in emergency departments in North Carolina, 2010-2011. North Carolina Medical Journal, 75(1), 8-14. https://doi.org/10.18043/ncm.75.1.8

Pavitt, M. J., Swanton, L. L., Hind, M., Apps, M., Polkey, M. I., Green, M., \& Hopkinson, N. S. (2017). Choking on a foreign body: A physiological study of the effectiveness of abdominal thrust manoeuvres to increase thoracic pressure. Thorax,
Vol. 72, pp. 576-578. https://doi.org/10.1136/thoraxjnl2016-209540

Phung, V.-H., Trueman, I., Togher, F., Orner, R., \& Siriwardena, A. N. (2017). Community first responders and responder schemes in the United Kingdom: systematic scoping review. Scandinavian Journal of Trauma, Resuscitation and Emergency Medicine, 25(1), 58. https://doi.org/10.1186/s13049-0170403-z

Qalil, A., Althubaiti, A., Altowairqi, R. M., Alsulimani, F. A., Alnefaie, B. M., Student, M., ... City, T. (2019). Awareness, knowledge, attitude and practices of first aid skills among medical and non-medical students at Taif University. 17(11).

Sasson, C., Haukoos, J. S., Bond, C., Rabe, M., Colbert, S. H., King, R., ... Heisler, M. (2013). Barriers and facilitators to learning and performing cardiopulmonary resuscitation in neighborhoods with low bystander cardiopulmonary resuscitation prevalence and high rates of cardiac arrest in Columbus, OH. Circulation: Cardiovascular Quality and Outcomes, 6(5), 550558. https://doi.org/10.1161/CIRCOUTC OMES.111.000097

Satrio, T. Y. S. P. A. C. U. I. T. (2018). Buku saku. https://doi.org/10.1016/j.ccl.2011.03. 002

The Asia Foundation. (2012). Gender in 
Indonesia. The Asia Foundation, 2, $1-2$.

Wang, J., Ma, L., \& Lu, Y. Q. (2015). Strategy analysis of cardiopulmonary resuscitation training in the community. Journal of Thoracic Disease, 7(7), E160-E165. https://doi.org/10.3978/j.issn.20721439.2015.06.09 